\title{
Каталонский судебный процесс в оценках британских медиа \\ (январь-март 2020 г.)
}

Григорий Прутцков

Наталья Андреева

В статье исследуется отношение ведущих британских средств массовой информации к теме каталонского кризиса. Практические шаги руководства Каталонии к независимости погрузили Испанию в ее самый глубокий политический кризис за последние сорок с лишним лет. Авторы приходят к выводу о том, что британские СМИ, анализируя события январямарта 2020 г., связанные с судом над бывшими руководителями правоохранительных органов Каталонии, в целом точно отражали ситуацию, не высказывая особых оценочных суждений. При этом события, проходившие в Верховном суде Испании, на фоне общей проблемы регионального сепаратизма были заслонены более важной для британских читателей проблемой Брексита и потому не вызвали существенного резонанса в медиапространстве Великобритании.

Ключевые слова: Каталония, региональный конфликт, каталонский кризис, медиа, референдум.

(c) Прутцков Григорий Владимирович кандидат филологических наук, доцент кафедры зарубежной журналистики и литературы факультета журналистики МГУ имени М.В. Ломоносова (г. Москва, Россия), pruttskov@gmail.com (c) Андреева Наталья Вадимовна выпускница магистратуры факультета журналистики МГУ имени М.В. Ломоносова (г. Москва, Россия), natashadrev@gmail.com

\section{Введение. История вопроса}

Борьба Каталонии за независимость длится уже три столетия и заметно активизировалась к середине 2010 гг. Попытка руководителей региона объявить в 2014 г. референдум о независимости от Испании была заблокирована официальным Мадридом. Референдум удалось провести лишь 1 октября 2017 г. Еще за несколько месяцев до его объявления власти страны признали этот акт волеизъявления незаконным, противоречащим конституции. В ходе референдума за независимость проголосовало 2044038 человек (90,18\%), против 177547 человек (7,83\%). Но при этом явка составила 43,03 \% от общего числа избирателей ${ }^{1}$. Конституционный суд Испании на чрезвычайном заседании, состоявшемся 6 сентября 2017 г., принял к рассмотрению иск правительства страны о незаконности принятых в Каталонии документов. К властям автономного сообщества был предьявлен ряд претензий:

- неизвестен источник финансирования референдума;

- незаконность принятых в Каталонии документов;

- беспристрастность плебисцита и противоречия в его процедуре, нарушающие устав Венецианской комиссии (европейского консультативного органа по конституци- 
онному праву): организацией плебисцита должен заниматься независимый и беспристрастный орган, а комиссия Каталонии включает в себя пять человек, напрямую связанных со сторонниками отделенияз;

- решение о проведении референдума противоречит Конституции Испании, согласно которой референдум не может проводиться без разрешения властей и общенационального референдума, не предусмотрен выход из состава Испании отдельных автономий ${ }^{4}$.

Власти Европейского союза также не стоят в стороне от конфликта, так как он напрямую касается не только Мадрида и Барселоны, но и Брюсселя. Представитель исполнительной коллегии ЕС Маргаритис Схинас официально предупредил руководителей Каталонии о том, что в случае провозглашения независимости этот регион может лишиться членства в Евросоюзе5.

Референдум 1 октября 2017 г. проводился под официальным запретом властей Мадрида - полицейские, присланные из столицы, противодействовали голосованию, мэрам городов было вынесено предупреждение о личной уголовной ответственности. Только 700 муниципалитетов Каталонии из 948 согласились провести голосование.

16 января 2020 г. в Национальном суде Испании начался процесс по делу бывшего руководства правоохранительных органов Каталонии, которым инкриминировалось противодействие решениям Конституцион ного суда Испании о запрете референдума о независимости. Среди обвиняемых - эксглава каталонских правоохранительных органов Mossos d'Esquadra ${ }^{6}$ Жозеп Льюис Траперо, бывший директор каталонских правоохранительных органов Пере Солер, бывший секретарь внутренних дел Женералитата7 Сезар Пуч, а также лейтенант Тереса Лаплана, которая руководила операцией Гражданской гвардии Испании в помещениях регионального правитель- ства Каталонии 20 сентября 2017 г. Первым трем обвиняемым грозит по одиннадцать лет лишения свободы за участие в мятеже. Тереса Лаплана может быть приговорена к четырем годам тюрьмы за подстрекательство к мятежу ${ }^{8}$.

\section{Судебный процесс в освещении британских СМИ}

Ситуация в Испании на современном этапе исторического развития - яркий пример процесса трансформаций внутри европейского пространства. Каталонский кризис является более значимой и фатальной угрозой для Евросоюза, чем даже выход 31 января 2020 г. Великобритании из ЕС. Поэтому данная тема не исчезает с полос ведущих европейских СМИ. Особенно пристальное внимание уделяют ей медиа тех государств, где так же, как и в Испании, существуют прямые или скрытые конфликты между титульной и малой нацией. Яркий пример - средства массовой информации Великобритании, страны, где проблема шотландского самоопределения на протяжении последних шести лет особенно остра и актуальна (подр. об освещении каталонского кризиса британскими СМИ см.: Прутцков, 2019). Среди основных участников событий британские медиакомпании обозначают, с одной стороны, руководство Испании, с другой - руководителей движения за независимость Каталонии.

Предметом нашей исследования стали три ведущие британские медиакомпании: The Guardian, BBC, The Times. Их публикации дают возможность понять, какие приоритеты присущи современному британскому медиапространству при трактовке социально-политического конфликтов в мире. В основе настоящей статьи - контент-анализ публикаций в период с 1 января 2020 г. по 17 марта 2020 г. ведущих британских СМИ: The Guardian, ВВС, The Times. Всего в данных медиа вышло 86 публикаций на тему судебного процесса бывших руково- 
дителей Каталонии. Все они были изучены при подготовке данной статьи. В процессе исследования использовался метод сравнительного анализа. В качестве эмпирической базы рассмотрены аналитические статьи экспертов, новостные сводки российских и зарубежных информационных агентств.

Пик публикаций по исследуемой теме пришелся на вторую неделю судебного процесса - с 21 по 27 января 2020 г. Подавляющее большинство британских СМИ подошли к освещению исследуемого материала весьма упрощенно, не анализируя, как повлияет данная ситуация на населении Каталонии, не задумываясь о том, приведут ли результаты судебного процесса к новым выступлениям против полицейского насилия. В то же время The Guardian, ВВС и The Times не стали скрывать от читателей, что своими резкими действиями премьер-министр Испании Педро Санчес только накаляет конфликт между Мадридом и Барселоной, отодвигая на неопределенное будущее взвешенный и аргументированный диалог руководителей Испании и Каталонии.

C 1 февраля СМИ стали реже, чем в январе, освещать новости Каталонии, а со второй половине марта практически полностью сконцентрировались на теме пандемии коронавирусной инфекции. Из-за коронавируса были отменены или отложены все мероприятия, в том числе и судебные заседания.

\section{Позиция The Guardian}

Рассмотрим позицию о суде в Каталонии газеты The Guardian. Это одна из старейших (основана в 1821 г.) газет в стране, придерживающаяся либеральных взглядов, и самое посещаемое в Великобритании электронное издание 9 . Всего с января 2020 г. по середину февраля 2020 г. по данной теме опубликовано 43 материала.

13 января 2020 г. The Guardian выпустила статью, где обозреватели газеты Джен- нифер Рэнкин и Кас Мудде рассказали о дальнейших шагах, которые хочет предпринять скрывающийся в Бельгии от испанского правосудия экс-глава Каталонии Карлес Пучдемон. Особое внимание газета обратила на болезненный для британских читателей пассаж о том, что Пучдемон надеется на поддержку других сепаратистских партий Европы, например левоцентристской Шотландской национальной партии и левоцентристской Партии Уэльса"1.

В статье The Guardian «Глава каталонской полиции предстает перед судом по обвинению в мятеже» от 21 января 2020 г. отображено текущее развитие событий судебного разбирательства12. Мадридский корреспондент Сэм Джонс изложил позицию Жозепа Льюиса Траперо, бывшего начальника каталонской полиции, отрицавшего свою близость к низложенному президенту Каталонии Карлесу Пучдемону, инициатору референдума о независимости от Испании 1 октября 2017 г. The Guardian отметила, что заявление Траперо может положительно повлиять на положение дел бывшего главы Каталонии.

Газета также предположила, что итоги данного судебного разбирательства повлияют на решение каталонского руководства о проведении нового референдума о независимости. По мнению The Guardian, после вынесения приговора четырем офицерам Mossos d'Esquadra население Каталонии может организовать серию протестов, которые в итоге вынудят власти принять решение о повторном референдуме. Если намечающийся референдум состоится после окончания судебного процесса и его результаты приведут к отделению Каталонии от Испании, это станет концом всего европейского проекта. Таким образом, оценивая серьезное давление, которое идет от испанской центральной власти на каталонцев, The Guardian отметила, что ситуация может стать еще более напряженной, чем сейчас. 
События января 2020 г. в Верховном суде Испании The Guardian комментировала как еще одну попытку испанских властей удержать Каталонию в составе Испании, т.к., в случае отделения региона, Испанию накроет экономическая катастрофа, поскольку Каталония является самым динамичным и богатым регионом страны ${ }^{13}$.

По данным корреспондентов информационного агентства Reuter's в Барселоне, авторов статьи «Лидер Каталонии лишен права голоса из-за протестов», опубликованной в The Guardian 27 января 2020 г., левая политическая партия Каталонии добилась лишения руководителя Каталонии Кима Торры права голоса в парламенте, но при этом сохранив его статус главы каталонского правительства. Данное решение было поддержано Верховным судом Испании. Лишение Торры права голоса в парламенте привело к протестам демонстрантов, не согласных с решением партии 14 .

10 февраля 2020 г. в статье Ройсина О'Брайен «Восстание Антигоны: движение желтых жилетов и организованные каталонские протесты создают новую мифологическую трагедию» речь шла о постановке хореографа из Барселоны Жоана Клевилле трагедии древнегреческого драматурга Софокла «Антигона». В статье описывалось, как испанские власти подавляют гражданскую инициативу жителей Каталонии. Хореограф выразил несогласие с позицией официального Мадрида по отношению к ситуации в целом и судебному процессу в частности. Он вспоминает референдум о независимости Каталонии в октябре 2017 г. и последовавшее за ним насилие с «чувством глубокого отчаяния и печали» и считает, что Мадрид злоупотребляет своими полномочиями, не разрешая Каталонии отделиться от Испании ${ }^{15}$. Газета критически оценивает позицию Жоана Клевилле, который, работая в Шотландии, подогревает подобными заявлениями и без того непростую обстановку в регионе.
Проведя анализ опубликованных статьей в The Guardian о каталонском судебном процессе, мы выяснили, что из 43 статьей в 13 не одобрялись действия правительства Испании, 30 статей имели нейтральную тональность, без каких-либо оценочных суждений, отражая только фактические события, происходившие на суде. По сравнению с другими ведущими британскими медиа The Guardian выпустила максимальное число материалов по данной теме. Только за вторую неделю судебного процесса с 27 января по 2 февраля 2020 г. - газета опубликовала 15 соответствующих статей.

\section{Позиция BBC}

Определим отношение еще одного авторитетного британского медиа - общенациональной общественной телерадиовещательной организации ВВС к теме каталонского суда. Всего по исследуемой тематике ВВС с января по середину февраля 2020 года опубликовала 28 материалов.

В статье «Педро Санчес: расцвет испанского премьер-министра» от 7 января 2020 г. Ричард Листер подчеркивает, что сепаратистские настроения Каталонии существенно влияют на внутреннюю политику Испании. В публикации также отмечено, что новый премьер-министр страны Педро Санчес остается в правительственном меньшинстве, следовательно, ему предстоит тяжелая работа по принятию новых законов. Партии консервативного толка и крайне правые выступают категорически против отделения Каталонии ${ }^{16}$.

16 января 2020 г., сразу после начала суда над бывшим руководством правоохранительных органов Каталонии, ВВС выпустила интервью Эндрю Нил с известным британским политиком-лейбористом Лизой Нэнди - «Шотландская независимость: кандидат от лейбористов Лиза Нэнди раскритикована за высказывания в адрес Каталонии». Британские журналисты уже не впервые экстраполировали каталонскую 
ситуацию на Шотландию, и это ожидаемо вызвало болезненную реакцию не только читателей, но и политических деятелей. «Мы должны обратиться к другим странам и другим частям мира, где руководителям государств пришлось иметь дело с раскольническим национализмом, - сказала в интервью Лиза Нэнди, - и попытаться извлечь уроки из тех ситуаций, как, например, сегодня в Каталонии, где удалось победить узкий раскольнический национализм через социальную справедливость». Далее политик высказалась о ситуации с непосредственным волеизъявлением граждан Каталонии: «Я думаю, что в этой стране было достаточно референдумов»17.

Сравнение Шотландии и Каталонии прозвучало и в статье Тома Симондса «Единственный шотландский депутат от лейбористов Иэн Мюррей отвергает раскол партии» от 19 января 2020 г.18 Шотландский политик-лейборист Иэн Мюррей высказался о негативном отношении к Каталонии кандидата от лейбористов Лизы Нэнди. Мюррей считает, что, используя дубинки и оружие в акциях за независимость Каталонии, правительство Испании не добьется мирных соглашений с гражданами этого региона. В этой же статье приведено мнение первого министра Шотландии Николы Стерджен, которая отметила, что жители Каталонии были «унижены» высказываниями Лизы Нэнди от 16 января 2020 г.19

В продолжение темы 19 января 2020 г. BВC опубликовала статью шотландского корреспондента Лорны Гордон «Независимость Шотландии: экс-министр Шотландской национальной партии Алекса Нила призывает к «консультативному» голосованию», в которой озвучена позиция Алекса Нила о том, что референдум октября 2017 г. за независимость Каталонии является незаконным, так как «всего избирателей было только 42\% граждан»20.

23 января 2020 г. ВВС выпустила еще одну статью Лорны Гордон «Понсати в роли евродепутата может остановить экстрадицию» об обвинении в подстрекательстве к мятежу известного профессора экономики, члена Каталонской национальной ассамблеи, советника по вопросам образования в правительстве Каталонии в 2016-2017 гг. Клары Понсати из-за ее роли в несанкционированном референдуме о независимости Каталонии в 2017 г. Ее адвокат Аамер Анвар заявляет, что Верховный суд Испании специально обвиняет Понсати, чтобы она не смогла выиграть выборы в депутаты Европарламента. Учитывая, что «Великобритания покинет Европейский парламент 31 января, а ее депутаты... потеряют свои места», правительство Испании таким образом пытается всеми силами не пустить в Европарламент депутатов с сепаратистками взглядами²1.

В статье Ричарда Листера «Каталония: экс-шефу полиции Траперо предъявлено обвинение в подстрекательстве к мятежу» от 27 января 2020 г. утверждается, что главный обвиняемый по этому делу - Жозеп Льюис Траперо, бывший глава Mossos d'Esquadra. По сведениям журналистов, он был уволен со своей должности в 2017 году, после четырех лет руководства, когда центральное правительство приняло на себя региональные полномочия в Каталонии в соответствии с 155 статьей Конституции Испании. Эта мера была осуществлена после одностороннего провозглашения независимости Каталонии. Жозепа Льюиса Траперо обвиняют в том, что он предпринял недостаточные действия для предотвращения проведения референдума.

В материале «Власти Мадрида объяви ли нового начальника полиции Каталонии» сообщается, что на шестой день судебного разбирательства, 21 января 2020 г., полковник Диего Перес де лос Кобос начал яростно критиковать действия Жозепа Льюиса Tраперо22. «Если бы я сам руководил Mossos d'Esquadra, моим первым решением было бы отстранить Траперо.., поскольку он пос- 
тоянно вставлял спицы в колеса», - сказал глава Гражданской гвардии суду ${ }^{23}$.

В публикации ВВС от 3 февраля 2020 г. отмечается, что Европейский союз не одобряет методы независимого отделения Каталонии от Испании, так как это, в свою очередь, может ударить по экономике всего Европейского союза24.

В целом журналисты ВВС сходятся во мнении, что стремление Каталонии к независимости погрузило Испанию в ее самый большой политический кризис за последние сорок лет. В случае отделения Каталонии от Испании Испания потеряет не только регион, но и снизит экономические показатели развития. При этом Европейский союз всегда выступает за территориальную целостность страны.

Таким образом, как было отмечено выше, с января 2020 г. по февраль 2020 г., ВВС выпустила 28 статей по данной тематике. Из них 18 статей критикуют действия Верховного суда Испании, заключившего под стражу бывшего главу Mossos d'Esquadra Жозепа Льюиса Траперо. Десять материалов нейтрально описывают судебный процесс над офицерами Котолонии Mossos d'Esquadra. Только ВВС в полном объеме осветила мнение полковника Диего Переса де лос Кобоса, который, в свою очередь, во время судебного процесса серьезно критиковал действия Жозепа Льюиса Траперо.

\section{Позиция The Times}

Тему каталонского суда освещало и другое авторитетное издание - The Times, старейшая британская ежедневная газета (основана в 1785 г.), традиционно придерживающаяся консервативных взглядов. У данного медиа с января 2020 г. по середину февраля 2020 г. по исследуемой теме насчитывается 15 статей.

4 января 2020 г. The Times выпустила материал Майки Перри «Каталонские сепаратисты поддерживают испанского Педро Санчеса», где рассказывается о том, что премьер-министр Испании Педро Санчес получил поддержку от партии сепаратистов (Esquerra Republicana de Catalunya), пообещав разрешить вопросы Каталонии в рамках конституции Испании, а не через испанские судебные инстанции 25 .

16 января 2020 г. The Times опубликовала статью Марка Маклафлина «Лейбористское руководство: “Следуйте примеру Испании, чтобы победить шотландских националистов", - высказывание Лизы Нэнди», в которой приводится мнение кандидата от партии лейбористов Лизы Нэнди, выступающей против независимости Каталонии: «необходимо победить узкий, раскольнический национализм, процветающий сейчас в Каталонии»26.

В статье журналиста Изамбарда Уилкинсона «Жозеп Луис Траперо, бывший начальник каталонской полиции, предстал перед судом за разрешение референдума о независимости» от 21 января 2020 г. подчеркивается, что судебный процесс в Мадриде над Жозепом Луисом Траперо и тремя другими офицерами проходит в «деликатный момент» для Педро Санчеса, чье правительство во многом зависит от поддержки каталонской сепаратистской партии.

The Times также отмечает, что в октябре 2019 г. Верховный суд Испании посадил в тюрьму девять лидеров Каталонии (газета называет их сепаратистами) за участие в незаконном референдуме, провозглашение независимости и подстрекательство к мятежу. Приведение приговора в силу вызвали массовые протесты населения. После того, как каталонский парламент опубликовал декларацию о независимости, Мадрид уволил Траперо, а также распустил региональное правительство и ввел в регионе временное правление 27.

По сравнению с The Guardian (43 статьи) и ВBC (28 статей) The Times осветила анализируемую тему в незначительной мере (15 статей), причем в течение второй не- 
дели судебного процесса было опубликовано всего пять материалов. Все статьи The Times имеют достаточно индифферентный характер по отношению кданному вопросу. Сравнение каталонской ситуации с Шотландией просматривается в The Times в меньшей степени, чем в The Guardian и в BBC.

\section{Заключение}

Анализируя публикации ведущих британских СМИ - The Guardian, BВС, The Times, можно сделать вывод о том, что все они в полной мере осветили тему каталонского судебного процесса. Данные медиа сходятся в том, что конфликт и беспорядки не окончатся мирным путем, так как сторонники независимости нацелены на отделение Каталонии; агрессивные действия властей Испании негативно отражаются на простых гражданах и на лидерах-сепаратистах; в то же время тема каталонского кризиса во многих публикациях рассматривается через призму ситуации в Шот- ландии с развитыми центробежными настроениями среди населения.

В данный момент, по оценке британских медиа, жители Каталонии выражают недовольство испанскими властями, причем не только в вопросе о независимости региона, но и в части распределения доходов. По мнению каталонцев, налогов в испанскую казну они платят намного больше, чем им возвращается из Мадрида в виде дотаций.

The Guardian, BBC и The Times отражали ситуацию по данному суду, в целом не имея особых оценочных мнений. События, проходившие в Верховном суде Испании, на фоне общей проблемы регионального сепаратизма не вызвали существенного резонанса в медиапространстве Великобритании. Однако это можно объяснить тем, что британцы в этот период были сфокусированы на Брексите, а также, примерно с конца февраля, на теме развития коронавирусной инфекции.

\section{Примечания}

1 Referendum d'Autodeterminació de Catalunya Resultats definitius. El Periódico. Peжим доступа: http://estaticos.elperiodico.com/resources/pdf/4/3/1507302086634

21 декабря 2019 г. Конституционный суд Испании начал рассмотрение иска правительства страны о незаконности резолюции о независимости Каталонии.

3 Устав Европейской комиссии за демократию через право (принята Комитетом министров 21 февраля 2002 г. на 784 заседании Постоянных представителей министров).

4 Хенкин С.М. Каталонский конфликт вчера и сегодня // Актуальные проблемы Европы. 2015. № 1. С. 117-138.

5 Suanzes P. Bruselas defiende la legalidad en España pero avisa: "La violencia no puede ser un instrumento en política". Режим доступа: https://www.elmundo.es/esp ana/2017/10/02/59d2139a468aeblc0f8b45a5.html (дата обращения: 06.07.2020).

6 Mossos d'Esquadra - Полиция Каталонии, которая в значительной степени заменяет в регионе Испанскую национальную полицию и Гражданскую гвардию.

7 Женералитат Каталонии - высший орган самоуправления Каталонии, включает в себя парламент и правительство региона, возглавляется президентом Женералитата, который выполняет функции главы Каталонии. 
8 Quién es quién en el juicio de Trapero: César Puig, Pere Soler y Teresa Laplana. Peжим доступа: https://www.elperiodico.com/es/politica/20200120/protagonistasjuicio-trapero-cesar-puig-pere-soler-teresa-laplana-7813616 (дата обращения: 06.07.2020).

9 The Top 500 Sites on the Web. Режим доступа: https://www.alexa.com/topsites/ category/Top/News (дата обращения: 26.02.2020).

10 The Guardian. Режим доступа: https://www.theguardian.com/international/ (дата обращения: 26.02.2020).

11 Rankin J. (2020) Ex-Catalan Leader Who Fled to Belgium Takes up European Parliament Seat. The Guardian, January 13. Режим доступа: https://www.theguardian.com/ world/2020/jan/13/puigdemont-arrives-to-take-up-european-parliament-seat/ (дата обращения: 29.02.2020).

12 Catalan Police Chief Appears in Court to Face Charges of Rebellion. The Guardian. 2020, Janyary 20. Режим доступа: https://www.theguardian.com/world/2020/ jan/20/catalan-police-chief-josep-lluis-trapero-denies-being-close-to-carlespuigdemont-spain/ (дата обращения: 08.07.2020).

13 Там же.

14 Protests as Catalonia's Leader Stripped of Voting Rights. The Guardian, 2020, January, 27. Режим доступа: https://www.theguardian.com/world/2020/jan/27/protests-ascatalonias-leader-stripped-of-voting-rights/ (дата обращения: 29.02.2020).

15 The Antigone Uprising: Gilets jaunes and Catalan Protests Spark New Myth. The Guardian, 2020, February 10. Режим доступа: https://www.theguardian.com/ stage/2020/feb/10/the-antigone-uprising-gilets-jaunes-and-catalan-protestsspark-new-myth/ (дата обращения: 29.02.2020).

16 Sánchez P. (2020) The Rise of Spainıs Battle-Scarred PM. BBC, January 7. https://www. bbc.com/news/world-europe-48012724/ (дата обращения: 29.02.2020).

17 Scottish Independence: Labour Candidate Lisa Nandy Criticised for Catalonia Remarks. ВBC, 2020. January 16. Режим доступа: https://www.bbc.com/news/ukscotland-scotland-politics-51139519/ (дата обращения: 29.02.2020).

18 SoleScotsLabourMPIanMurrayrejectspartysplit.BBC,2020.January 19.Режимдоступа: https://www.bbc.com/news/uk-scotland-scotland-politics-51168815/ (дата обращения: 29.02.2020).

19 Там же.

20 Scottish Independence: Ex-SNP Minister Alex Neil Calls for 'Consultative' Vote. BBC, 2020. January 19. Режим доступа: https://www.bbc.com/news/uk-scotlandscotland-politics-51167183/ (дата обращения: 29.02.2020).

21 Ponsati's Role as MEP 'Could Halt Extradition'. ВBC, 2020, January 23. Режим доступа: https://www.bbc.com/news/uk-scotland-51230674/ (дата обращения: 29.02.2020).

22 Catalonia Referendum: Madrid Moves to Take Over Local Policing. BBC, January 27. Режим доступа: https://www.bbc.com/news/world-europe-41373977/ (дата обращения: 27.02.2020).

23 Там же. 
24 Scottish Independence: How Brexit Has Changed the Debate over EU Membership. ВВC, February 3. Режим доступа: https://www.bbc.com/news/uk-scotland-scotlandpolitics-51357050/ (дата обращения: 29.02.2020).

25 Catalan Separatists Renew Support for Spain's. Sanchez. The Times, 2020, January 4. Режим доступа: https://www.nytimes.com/2020/01/04/world/europe/pedrosanchez-catalonia.html/. (дата обращения: 29.02.2020).

26 Labour Leadership: Follow Spain's Example to Defeat Scottish Nationalists, Lisa Nandy Says. The Times, 2020, January 16. Режим доступа: https://www.thetimes. co.uk/article/labour-leadership-follow-spains-example-to-defeat-scottishnationalists-lisa-nandy-says-gnqpcbvrp/ (дата обращения: 29.02.2020).

27 Josep Lluís Trapero, Former Catalan Police Chief, on Trial for Allowing Independence Referendum. The Times, 2020, January 21. Режим доступа: https://www.thetimes. co.uk/article/former-catalan-police-chief-on-trial-for-allowing-independencereferendum-zp8nsqjqr/ (дата обращения: 27.02.2020).

\section{Библиография}

Прутцков Г.В. Особенности освещения референдума о независимости Каталонии в прессе США и Великобритании // МедиаАльманах. 2019. № 1. С. 147-160. 